Meta

Journal des traducteurs

Translators' Journal

\title{
Film Studies and Translation Studies: Two Disciplines at Stake in Audiovisual Translation
}

\section{Frederic Chaume}

Volume 49, numéro 1, avril 2004

Traduction audiovisuelle

Audiovisual Translation

URI : https://id.erudit.org/iderudit/009016ar

DOI : https://doi.org/10.7202/009016ar

Aller au sommaire du numéro

Éditeur(s)

Les Presses de l'Université de Montréal

ISSN

0026-0452 (imprimé)

1492-1421 (numérique)

Découvrir la revue

Citer cet article

Chaume, F. (2004). Film Studies and Translation Studies: Two Disciplines at Stake in Audiovisual Translation. Meta, 49(1), 12-24.

https://doi.org/10.7202/009016ar
Résumé de l'article

Les textes audiovisuels sont habituellement construits selon les conventions du langage cinématographique, un langage qui intègre mais dépasse la dimension verbale et qui possède ses propres règles et conventions. Un tel langage est composé de plusieurs codes de signification. Dans cet article, l'accent est mis sur l'interaction des codes non linguistiques à la fois dans le langage cinématographique et dans la traduction audiovisuelle. L'auteur soutient que les contributions de la traductologie et des études filmiques sont nécessaires pour analyser les textes audiovisuels dans une perspective traductionnelle, analyse pour laquelle existent déjà différents modèles. Il offre cependant un nouveau cadre d'analyse tiré des études filmiques et présente les codes de signification qui affectent la traduction. Ces codes sont illustrés par un certain nombre de signes non linguistiques et leur représentation dans le texte, ces signes influençant la traduction.
Ce document est protégé par la loi sur le droit d'auteur. L'utilisation des services d’Érudit (y compris la reproduction) est assujettie à sa politique d'utilisation que vous pouvez consulter en ligne.

https://apropos.erudit.org/fr/usagers/politique-dutilisation/ 


\title{
Film Studies and Translation Studies: Two Disciplines at Stake in Audiovisual Translation
}

\author{
FREDERIC CHAUME \\ Universitat Jaume, Castelló, Spain \\ uji00096@uji.infomail.es
}

\begin{abstract}
RÉSUMÉ
Les textes audiovisuels sont habituellement construits selon les conventions du langage cinématographique, un langage qui intègre mais dépasse la dimension verbale et qui possède ses propres règles et conventions. Un tel langage est composé de plusieurs codes de signification. Dans cet article, l'accent est mis sur l'interaction des codes non linguistiques à la fois dans le langage cinématographique et dans la traduction audiovisuelle. L'auteur soutient que les contributions de la traductologie et des études filmiques sont nécessaires pour analyser les textes audiovisuels dans une perspective traductionnelle, analyse pour laquelle existent déjà différents modèles. Il offre cependant un nouveau cadre d'analyse tiré des études filmiques et présente les codes de signification qui affectent la traduction. Ces codes sont illustrés par un certain nombre de signes non linguistiques et leur représentation dans le texte, ces signes influençant la traduction.
\end{abstract}

\begin{abstract}
Audiovisual texts are usually built according to the conventions of film language, a complex language that overcomes linguistic communication and has its own rules and conventions. In film language it is possible to distinguish several signifying codes which complement and frame words and linguistic meaning. This paper will focus on the interplay of non-linguistic codes in film language and audiovisual translation. In the first place, I will argue that for the analysis of audiovisual texts from a translational perspective at least the theoretical contributions of Translation Studies and those of Film Studies are necessary. Then, I will review the different models of analysis of audiovisual texts offered from the perspective of Translation Studies. Finally, I will introduce a new paradigm based on Film Studies, and present the signifying codes that primarily affect translation operations in the transfer. I will also illustrate these codes with a number of non-linguistic signs and their representation in the text, and will finally discuss the influence of such signs on translation operations.
\end{abstract}

\section{MOTS-CLÉS/KEYWORDS}

audiovisual text, dubbing, film language, model of analysis, signifying codes

\section{The need for an interdisciplinary approach in audiovisual translation}

The methodology used in audiovisual translation research should involve a multidisciplinary approach allowing for a rigorous analysis of the object under study. Indeed, due to their hybrid nature from a textual and generic point of view - since it is difficult to define where one genre ends and another begins - and also from the sheer variety of possible content, and the multiple signifying codes operating 
simultaneously, that are involved in the production of significance, audiovisual texts encourage analysts to use various approaches to better understand the relationship between the elements that make up the object of their study, and the key textual and contextual issues that need examining when transferring elements to another language and culture.

In this article I will argue that for the analysis of audiovisual texts from a translational perspective at least, the theoretical contributions of Translation Studies and those of Film Studies are necessary. Both disciplines are crucial in the exegesis of audiovisual texts and become necessary in order to understand the interlaced web of meaning in these texts. It would seem unnecessary to justify the relevance of translation theory to any application or description involving that discipline; however, it is important to highlight those aspects that studies of audiovisual communication draw attention to in the analysis of audiovisual texts, a knowledge of which can impact directly on the translation process. First, I will justify the reason why I am using a model of analysis in the first place. Then, I will describe the different approaches that audiovisual texts have received from a translational perspective. Lastly, I will state my proposal for a translational model of analysis, centred on signifying codes in film language with illustrations of the incidence of these codes in the translation process. This approach will make it easier to demarcate areas where these disciplines intersect and my textual analysis will show itself to have benefited from both approaches.

\section{An integrated model of analysis: an unresolved matter}

A model of analysis is justified due to the need to examine an object of study in a closer, more systematic way. First, a description of the object is sought, an exercise that could be viewed as an end in and of itself. It is also possible to use the results of the description for applied purposes (teaching, criticizing and evaluating translations, etc.). Given the growth of translation and interpreting degrees throughout Europe and the rise in the number of audiovisual translation courses within these degrees (notably in Spain), the demands for a model of analysis for audiovisual texts from a translation studies perspective is even more urgent. A model of analysis based on systematic approaches is also what should differentiate research into translation and the teaching of translation at universities from the traditional auto-didactic methods so common to the professional practice. Such a model should have the objective of focusing the object under study by using systematic approaches and a methodology based on inter-subjective approaches (rules, norms). Furthermore, if we wish the model to be useful in the teaching of translation, it should be able to a) show translators the tools (translation strategies and techniques) with which they will be able to confront their task, and b) reduce to a minimum the need for improvisation, but not for creativity.

The automation of the translating process by a working professional, however, makes any operational model unnecessary for the self-taught translator, since, on the one hand, the professional translator has already unconsciously assimilated translation strategies and techniques when faced with the most common translation problems and, on the other, the professional practitioner cannot afford an academic analysis due to the lack of time available for the task. A model of analysis is therefore more suited to the analyst, the translation researcher, and also for the apprentice translator 
or the student. Translation students, like those in any other discipline, need criteria which can help with their approach to the analysis of the topic they are studying. I do not foresee students applying any systematic analysis model when they become practicing professionals, but rather using it to learn in previous stages how to analyze the source text and automate the relationship between that analysis and translation strategies.

\section{Models of analysis of audiovisual texts}

Very few authors have explicitly elaborated a model of analysis aimed at translation studies undergraduates or researchers investigating the particular field of audiovisual translation. The models mentioned below, therefore, are not, strictly speaking, all "models of analysis" as such. Perhaps their authors would not recognize them as such, but rather as research lines into audiovisual texts with methodological intentions. However, I feel it is appropriate to consider these lines as models of analysis because, to a greater or lesser extent, they establish the foundations of what could end up being a proposal for a model of translational analysis. In some cases this intention is explicit, while others are methodological proposals on which to base research into audiovisual translation.

Leaving apart the articles published in Babel in 1960, which inaugurate research in audiovisual translation, the first articles about audiovisual texts from a translation studies perspective centred their attention on those specific aspects of the texts that differentiate them from other types of texts. These were research papers that proposed a methodological approach based on the constraints which the translator faces when trying to transfer the information from an audiovisual text into another language. It is worth mentioning, in this context, the pioneering works of Titford (1982) and Mayoral, Kelly, and Gallardo (1988). This latter work clearly notes the fundamental constraints that operate during the process of translation of audiovisual texts. Zabalbeascoa's model (1993) adds another dimension and contributes the idea of translation priorities (from a functional perspective), presenting a position that balances the position based on constraints.

One of the approaches that tries to incorporate both the assumptions of Translation Theory and Discourse Analysis is that based on the analysis of genres and types of audiovisual texts. In this respect it is worth highlighting Agost's works (1997 and 1999a), or specific works on a certain genre such as Agost (1999b) or Franco (2001). These studies focus on an analysis of the source text in accordance with the audiovisual genre to which it belongs. In a second step, once the generic characteristics have been recognised, it should be possible to establish "the main problems that a translation of a text will present" (Agost, 1997:304). Once these generic characteristics have been established, however, there is still a long road to travel before we can prove their effectiveness and applicability in the translation process.

Many of these approaches to the audiovisual text also have a pedagogical purpose. From among the analysis models that concentrate on the specificity of the audiovisual text from a didactic perspective, those of Espasa and Bartrina (forthcoming) and Bartrina and Espasa (2001) are worth mentioning. These are characterized by an attempt to analyze the audiovisual text as much from a professional viewpoint (i.e. real translation situations), as from the technical aspect characteristic of this type of 
translation (i.e. the global process involved in the work), and from an ideological and cultural perspective (i.e. language policies), all of which are aspects that condition the translation operation. Horizontally, these aspects are analyzed through the study of audiovisual genres that are most frequently translated under the discursive approach of the contextual dimensions proposed by Hatim and Mason (1990).

Descriptive studies have also notably influenced the analysis of translated audiovisual texts. Polysystemic methodology has borne fruit in descriptivist works from which models of analysis of audiovisual texts have been drawn from the standpoint of the translated text and not so much from the perspective of its fidelity with regard to the source text. In this context, it is worth noting the models proposed by Díaz Cintas (1998) or Izard (1999) that not only impact on the analysis of the linguistic and textual elements of the target text, but on the macro-textual elements that can offer a description of the historical, economic, and social framework in which the target text was composed and in which the translation operations took place. This encompasses the presentation of the translated product, which can already offer us indications of the translation method, to the analysis of the linguistic register used or the relationships between different genres and translations. This line of reasoning is shared by the studies of a historical perspective of Ballester (2000 and 2001) and of Gutiérrez (1999, 2001), centred both on macro-textual questions (political issues, economic issues, reasons for censorship, etc.), as well as on specific micro-textual questions (as in the interesting segmentation units of the source text and of the censored target text, in Gutiérrez's model).

A key work in this field is undoubtedly Karamitroglou (2000). The author proposes a model of analysis based on Even-Zohar's adaptation of Jakobson's wellknown scheme of communication. Karamitroglou extends the model, which is presented as the interaction of factors constituting the $\mathrm{x}$ axis or horizontal rows (i.e. human agents, products, recipients and audiovisual mode), and levels or subsystems (an adaptation of Even-Zohar general concept of sections), which constitute the $y$ axis or vertical columns. These levels stand for the three different subsystems which constitute the general polysystem: the target translation system, the target audiovisual translation system and the particular translated audiovisual text or group of texts. These levels also define the degree of importance or hierarchy of the factors that condition the appearance of norms. The author analyzes each factor in detail: the human agents in AVT (i.e. producers, addressers), the products or translated target texts (i.e. messages) considered from a semiotic perspective (not just linguistic), the recipients (i.e. addressees, consumers), not the public in general, but "that group of the general public that have consciously consumed the product and to which the target product is addressed" (76), the audiovisual mode (i.e. repertoire, mode) which makes audiovisual texts different from other modes (i.e. interpretation, written translation, etc.), the institution (i.e. context) or critics, film majors, distributors, TV channels, etc., which "intervenes at the pre-production stage by reflecting previous post-consumption established options" (81), and finally the market (channel) or theaters, video-clubs, the whole network of consumers who "intervene at the postproduction stage by placing a pre-consumption filter" (81), although in his view, both institution and market can be included within the categories of agents or recipients, respectively, according to their occasional status of agents or recipients in the translation process. After this, the author analyzes the function of his model/system by 
stressing the heterogeneous network of relations and levels that build the system and its position in a broader polysystemic context. As is the usual case with descriptive approaches, most studies are focused on choices at the macrostructure of the text, avoiding detailed studies on microtextual relations. Studies on the choices at the macrostructural level reveal ideological choices based upon political or economical agendas that govern translation choices in general terms, but that connect with professional practice with difficulties. The translator's daily task and the translator trainees' needs are usually left aside by polysystem theorists.

Another group would include those models of textual analysis on general translation, which are applied to a particular corpus of audiovisual translation (Herbst, 1987; Delabastita, 1989; and Whitman, 1992). Herbst's model (1987) is centred on the problems of lip synchrony and on those of what he calls nuclear synchrony, a term that subsumes both kinesic synchrony and isochrony (Whitman, 1992). It is also a model based on the equivalence of genre, of text quality, of content (more than form), of language variation and of cultural context. Delabastita's model (1989) is based on two axes, one of them being the techniques involved in textual construction in classical rhetoric (repetitio, adiectio, detractio, substitutio, transmutatio), and the other the verbal and non-verbal signifying codes transmitted by the acoustic channel and the visual channel. Therefore, translations can be analysed according to the technique or techniques employed in the transfer of the different elements belonging to each code. Whitman's model (1992) is an eclectic model that includes semantic and syntactic questions, problems of register, and pragmatic and cultural issues. Strictly speaking, none of these is a model of textual analysis specifically aimed at the analysis of audiovisual texts, although they have all been (or can be) applied to corpora of audiovisual texts.

I am interested in a new possible method of analysis of audiovisual texts, that is, an analysis of the texts focused on the signifying codes of cinematographic language. I am seeking, here, to establish a bridge between Translation Studies and Film Studies, and to check whether knowledge of cinematographic components can better explain audiovisual translation operations.

\section{A framework of analysis based on signifying codes of film language}

The factors noted by the authors mentioned above, among others, are all necessary for a comprehensive analysis of a text. A framework of analysis whose aim is to take into account the overall meaning of a text should, therefore, look both at the text's external factors (i.e. professional, historical, reception, communication, means of exhibition, etc.), and those "general" translation problems that will share the analysis of any text from a translational perspective (i.e. linguistic, contextual, pragmatic, cultural, etc., problems). However, many of the aspects that single out an audiovisual translation are not specifically included within these two areas.

An audiovisual text is a semiotic construct comprising several signifying codes that operate simultaneously in the production of meaning. A film is composed of a series of codified signs, articulated in accordance with syntactic rules. Its typology, the way it is organised and the meaning of all its elements results in a semantic structure that the spectator deconstructs in order to understand the meaning of the 
text. What interests the translator is knowing the functioning of each of these codes, and the possible incidence of all signs, linguistic and non-linguistic, within a translation (Chaume, 1997). In this last section, I will demonstrate via examples that these signifying codes can directly impact on a translation.

\subsection{The linguistic code}

It is obvious that without the presence of a linguistic code in a text we would not be able to speak of a process of translation properly. It is also true that the linguistic code is a signifying code shared with all texts that can be translated, which means that its analysis is not specific to an audiovisual orientation. However, what singles out the linguistic code in audiovisual texts is that in films, television series, cartoons, and certain advertisements, we are faced with a written text that has to appear oral and spontaneous (written to be spoken as if not written, according to the already classic definition of Gregory and Carroll, 1979). The balance between a written speech and making that speech sound oral and spontaneous is not easy to achieve. Television style books on audiovisual language (in Spain, Mendieta, 1995, Televisió de Catalunya, 1997) usually contain specifications and advice for the translator in this field. In a previous research (Chaume, 2001), the features peculiar to each linguistic level were examined and it was concluded that in each level certain features characteristic of the standard language could be found (i.e. avoiding elisions $-{ }^{*}$ could $a-$ and assimilations - ${ }^{*}$ gimme - in the translation, avoiding notional concord in the translation, or avoiding the segmentation of utterances and elisions of markers in the translation), as well as certain features that are characteristic of colloquial oral registers that endow a text with verisimilitude and liveliness (the abundant use of interjections, topicalization, and, most especially, the use of spontaneous lexical creation, of intertextuality, of clichés and stereotyped formulas, of social and professional slang, etc.). In conclusion, I am referring here about learning to rewrite a script so that it sounds as true as the original, maintaining a balance within the terms that I have pointed out above. The remaining problems that an audiovisual text can present for a translator in the linguistic field (i.e. word play, the simultaneous use of several languages, cultural elements) are shared by other translation types (e.g. legal, scientific, technical, etc.), and should not be considered problems specific to audiovisual translation.

\subsection{Paralinguistic codes}

Translators that also carry out the synchronization of dialogues, especially in the case of translation for television, should be familiar with a series of symbols that they must include in their translation and whose use is a matter of convention among synch editors or synch assistants. Many of these symbols represent certain suprasegmental features. In Spain, for example, laughter is usually represented with an (R) in brackets in dubbing, paralinguistic signs (i.e. differentiators, alternants, etc.) with a $(\mathrm{G})$ into brackets, and silences and pauses with a forward slash $(/)^{1}$. In subtitling, certain ortho-typographical uses also exist, such as dots or suspension points, subtitle cuts, the use of capital letters, etc., which also represent paralinguistic signs (silences, pauses, volume of voice, respectively). Topicalization can also be a translation technique to hint at a primary quality of the voice (volume, protesting tone). 


\subsection{The musical code and the special effects code}

Songs that appear in films usually require an adaptation in the translation that matches the rhythm of the music in accordance with the four poetic rhythms of classical rhetoric (i.e. rhythm of quantity or number of syllables, rhythm of intensity or accentual distribution, rhythm of tone and rhythm of timbre or rhyme). The analysis of the lyrics of a song cannot be carried out outside the sheet music that accompanies it. Within the field of dubbing, and also within that of subtitling, songs often work as narrative punctuation signs and usually involve a take cut (the translator uses a new dubbing unit or take for the song), or a subtitle change (the translator does not mingle lyrics and dialogues in the same subtitle). Italics are usually used in the representation of song lyrics in subtitling, a common ortho-typographical convention in the profession. Lastly, the translator usually also represents the special effects that are not recorded on the soundtrack of the film: in dubbing this is done by means of a conventional sign, such as a $(G)$ in Spain, or by a description of the effect in brackets such as (whistles), (applauses), etc.

\subsection{The sound arrangement code}

This is the last of the codes that are transmitted by the acoustic channel with a direct impact on the translator's task. In an audiovisual text in which a story is being told, sound can be diegetic (or belonging to the story) or non-diegetic (belonging to a person or object which is not part of the story, as an off-screen narrator). At the same time, sound can be produced on-screen (associated with the vision of the sound source) or off-screen, when its origin is not present in the frame and therefore not visible simultaneously with the perception of the sound. In these cases, the translator also doing the adaptation (dialogue writing) uses the symbol (ON) when the on screen source of the sound is perceived, and the symbol (OFF) when the sound source cannot be perceived. Other symbols that mark variations in the sound exist and they can be useful for the sound engineer or mixer: in television the symbol (DE) introduces in Spain an utterance by an actor with their back to the camera (the sound engineer usually adds a reverberation effect in such cases); or the symbol (DL) which usually introduces an utterance by a person in long shot (with corresponding sound effects). In the field of subtitling, the use of italics, for example, can also mark sound coming from OFF screen. Apart from technical considerations, it is worth noting that on-screen dialogues have to fit the screen characters' mouths (lip synchrony and isochrony), whereas off-screen dialogues allow the translation to produce freer nonconstrained solutions for the translation problems posed by the source text. Problems related to lip synchrony will be dealt with below (in 4.7. and 4.8. respectively).

\subsection{Iconographic codes}

The iconographic code is the most relevant code transmitted via the visual channel. The problem for translators consists of representing icons, indices, and symbols in the translation. The general norm with respect to these iconographic symbols is usually not to translate them (i.e. not to represent them linguistically) unless they are accompanied by a verbal explanation or their deconstruction is considered essential for 
understanding the story. In these cases, translators usually attempt to represent the icon linguistically within the translation, or to make some indirect reference to it within the dialogue, to just give one example, substituting a deictic expression that signals the icon in the source text for its full name in the target text. The challenge for the translator, in cases involving translation of a text associated with icons, is usually to achieve a translation that respects coherence with the image, that is to say, to add or include in the translation some linguistic sign that is more or less directly related to the icon on the screen. For example, if a translator is faced with a joke about guns which is also illustrated on screen with an icon representing a gun, his/her joke in the translated version will probably have to deal with guns too, something that might not be so problematic when translating written texts, which possibly allow a functional translation of the joke. In this sense, it is possible to affirm that audiovisual translation differs from other types of translation in that the non-existence of an image tied to the verbal text in these other types allows for free translation of an existing sentence, or a play with words, or a joke, for example, without this causing errors of coherence within the semiotic construction of the target text.

\subsection{Photographic codes}

The translator that carries out the synchronization of the translation, as well as the translator of subtitles, also represents, within the translation, changes in lighting, in perspective, or in the use of colour (i.e. colour vs. black and white, intentional use of certain colours, conventional meaning of colours, etc.). Changes of lighting can be accompanied in Spain by the use of the symbols ON (on screen sound), OFF (off screen) or SB (i.e. the character is on screen, but his/her mouth is not seen), with a corresponding relaxation of the synchronization (e.g. lip synchrony and isochrony) on the part of the translator and the actors, that is to say, with considerable more freedom when suggesting a translation of the OFF segments. Changes in lighting can also make necessary the different uses of orthotypography in subtitling (italics in dark scenes in which we do not know the identity of the character speaking, order of the subtitles according to characters, etc.). Perspective changes in science fiction films or in oneiric scenes, for example, can lead to erroneous usage of certain dubbing symbols such as those that mark proxemic signs (in Spain DC and DL). The deliberate use of black and white, rather than colour, for example, can imply changes from the real world to the imaginary world, as in the case of The Wizard of $\mathrm{Oz}$ (Victor Fleming, 1939), or the desire to narrate a story stripped of all artifice, as in certain Woody Allen films. The use of a certain colour as a microsign or culture-bound element can also impact directly on the translation. A colour that has certain associations in one culture might not have those same associations in another culture, such as the different colours associated with mourning, or a pun based on the name of a colour that is included as a visual gag on screen. In these cases the translator's solution to this problem will then be necessarily restricted or subordinated to this visual code.

\subsection{The planning code (types of shots)}

The planning code is especially significant in dubbing. In close-ups and extreme close-ups, the translator, by convention, usually has to find a text that respects the 
opening and closing of the lips of the character on screen. This is known as phonetic or lip synchrony. This exercise requires a creativity similar to the one required in choosing rhymes. The translator should maintain the impression of verisimilitude fitting the open vowels and bilabial consonants into those instants in which the person on the screen in close-up shot visibly opens his/her mouth or closes his/her lips in order to articulate a bilabial vowel or consonant respectively. On these occasions, the necessity of achieving good lip synchrony guides the translation solutions. Fortunately for the translator, these cases are not very numerous in audiovisual texts. In subtitling, this explicit demand does not exist; there is no need for phonetic synchrony. However, the use of certain shots can also directly affect the translation. For example, if a poster appears in close-up, the spectator who cannot understand the source language awaits to be offered a translation of this poster. Otherwise they may lose the thread of the narrative temporarily. However, if the poster does not appear in close-up, its relationship with other signs in the scene diminishes the relevance of the information that it contains, which means that the translation is not so necessary in a functional sense.

\subsection{Mobility codes}

Among mobility codes, those of special interest to the translator are proxemic signs, kinetic signs and the screen characters' mouth articulation. In the case of audiovisual texts, proxemic signs deal with the distance of the characters to each other, as well as the distance from the characters to the camera. This latter aspect is partly dealt with above in the section on close-ups and extreme close-ups (see 4.7.), but it also covers mid-shots, group shots and shots in which the character or characters are seen photographed in a distant position. In these latter cases, the conventions of Spanish dubbing advise the use of the symbol (DL) which means from a distance, from far away, and advises the actor doing the dubbing that a perfect synchronization in terms of isochrony (i.e. number of syllables) is not necessary - the equivalent duration of the original utterance with the dubbed utterance need not be exact. The symbol (DE) meaning with back turned, from behind, is used when the character has his back to the camera, and has the same function as the above. In subtitling, when the translator is faced with several people (three or more) speaking at once, the distance of the characters from the camera could be the criterion for selecting which lines to put into subtitles. For example, when three or more characters speak simultaneously, the translator can only represent a maximum of two characters in each subtitle (a single line for each character). In these cases the selection approach can be to choose the speech of the person or persons nearest to the camera (and hence the spectator), given that they are probably placed there for a reason (a motivated choice) and that their position has to do with the relevance of what they are narrating.

With respect to the representation of kinetic signs, in dubbing the translator must observe the movements of the characters on screen so that the translation adapts to the conventional meaning transmitted by these signs. Thus, the kinetic sign representing the negation with the head should be accompanied by a negative phrase in the translation. In other cases, the topicalization of some element in the translation is advisable in order that it appears simultaneously with the gesture made by the character. 
As for the representation of phonetic articulation, the opening and closing of the mouths of the characters on screen mark the duration in time and the approximate number of syllables in the utterances of the target text. In other words, the translation of each utterance should fit into the time it takes the actor on screen to say his/ her dialogue lines in the source language, from the moment the first mouth movement is seen, to the moment in which the mouth closes definitively. This is known by the term isochrony, or equivalent duration of the source text utterances and the utterances of the target text. Again, respect for the isochrony in a dubbed work is an endeavour to maintain a realistic effect and make the product more credible. In subtitling, this procedure receives the more widely known term of synchronization. The presence of a subtitle on the screen is made to coincide, more or less with the original dialogue, although the achievement of this is not nearly as strictly enforced as in dubbing. However, synchronisation is almost compulsory when the text of the subtitle is uttered by a character who is speaking on screen at that moment. Otherwise it would be difficult for the audience to relate subtitles to the characters' speeches.

\subsection{Graphic codes}

Likewise, conventions and translation norms exist to represent the written language appearing on the screen. The spectator perceives written language (captions) in the form of titles, intertitles, texts, and subtitles. The presence in a film of these four conventional genres directly influences the translation, since most of the time the translator needs to transfer their meaning to the target text, within the formal constraints that each one of them brings with it. The following chart summarizes the conventions used in the chosen format for the transfer of graphic codes in Spain:

\begin{tabular}{|c|c|c|c|c|}
\hline Mode Genre & Intertitles & Titles & Texts & Subtitles \\
\hline DUBBING & $\begin{array}{l}\text { a) Voice Off } \\
\text { b) Subtitled } \\
\text { c) Insertion of } \\
\text { new text in target } \\
\text { language }\end{array}$ & $\begin{array}{l}\text { a) Voice Off } \\
\text { b) Subtitled } \\
\text { c) Insertion of } \\
\text { new text in target } \\
\text { language }\end{array}$ & $\begin{array}{l}\text { a) Voice Off } \\
\text { b) Subtitled } \\
\text { c) Insertion of } \\
\text { new text in target } \\
\text { lang. }\end{array}$ & Subtitled \\
\hline SUBTITLING & Subtitled & Subtitled & Subtitled & Subtitled \\
\hline
\end{tabular}

The translation of different graphic codes will come conditioned both by the client's instructions, who might or might not want to translate the information conveyed by certain codes, and the relevance in the film of the title in question, something that will also be related to the shot in which it appears (planning code), the icon or icons, indexes or symbols which appear simultaneously (iconographic codes), the lighting used in the scene in question (photographic code) etc.

\subsection{Syntactic codes (editing)}

Being aware of iconic associations can help the translator to better understand the audiovisual text, the relationship of one scene to another and the position of the scene within the development of the plot and the narrative. The process of shot associations 
chosen by the director can have repercussions on the translation. In cases such as the visual and verbal repetition of an icon, problems caused by the excessive length of the translation (problems of isochrony) might be solved by the use of a pronoun, a synonym or an ellipsis in the translated text. A translation problem within a certain scene might be solved by actually watching the whole scene or later scenes, because the montage, as an operation creating meaning, can cast light on the appropriate solutions for the problem in question. That is to say, when the translator knows what procedure is being used in associating images, he or she can then select the most appropriate term based on the visual information that the viewer will see a few seconds or minutes later, avoiding, in this way, incoherent or politically incorrect solutions, etc. For example, in Sarafina (Darrell James Roodt, 1992), a musical on South-African apartheid, a white soldier refers to a black teacher as a rotten apple who is instigating her students to rebel against the apartheid. The Spanish bilingual dictionary offers two possibilities for the translation into Spanish of rotten apple: manzana podrida (rotten apple) and oveja negra (black sheep). When the soldier finishes his speech, the spectator is shown a scene change after which the black teacher is actually instigating her students to rebel. Before watching the teacher, the translator could have opted for both translation solutions in Spanish. After watching the next scene, politically correctness advises to opt for the first solution, as the second one can arbitrarily hurt the feelings of black spectators. This second solution could have been chosen in the translation of a novel, or in the translation of a written text, but it is not advisable in the translation of an audiovisual text, since the overwhelming presence of a close-up of the teacher after the scene change would add an unwarranted extra meaning, which was not in the director's or the scriptwriter's minds.

Also of special interest are the so-called audiovisual punctuation marks, such as fade to black or fade-outs, wipe-offs, iris, juxtapositions, etc. When faced with these signs in dubbing, the translator generally finishes a take and begins a new one, that is to say, dialogues uttered after the audiovisual punctuation mark will be included in a new take or dubbing unit, as the mark involves a narrative change In subtitling, the translator will finish his/her subtitle and produce a new subtitle after the punctuation mark.

\section{Conclusion}

The approach with which I attempt to analyse the audiovisual text is based, therefore, on joining together Translation Theory, Discourse Analysis and, especially, Film Studies and Communication Studies, and from there to conclude that the linguistic code, despite its predominant role, is but one more code at play in the construction and later transfer of meaning in audiovisual texts. As I have intended to show throughout this article, for the translator, knowledge of all the signifying codes present in the audiovisual texts is extremely relevant. Apart from the descriptive analysis of these codes, the translator should be particularly interested in the incidence of the different signifying codes within the linguistic one, since this is the only code that can be manipulated at all. A translation that does not take all the codes into account can be seen only as a partial translation. 
In this article I have noted some of the characteristics of signifying codes that integrate the semantic web of an audiovisual text, along with some of the repercussions of their associated meanings in the translation. It is especially of interest for the analyst to observe the interaction between all the signifying codes, since this interaction singles out the semantic potential of the audiovisual text and its texture or grammaticality. The meaning of each code, and the extra meaning created when interacting with other signifying codes in every moment, gives an audiovisual text its particular idiosyncrasy and sums up the specificity of audiovisual texts from a translational viewpoint.

The relationship between image and word, the interplay of the signification systems of audiovisual texts, shows itself in terms of cohesion and coherence between the two simultaneous narratives, the visual and verbal, in such a way that the translator finds himself/herself obliged to put into practice translation strategies capable of transmitting not only the information contained in each narrative and each code -as has been noted throughout this work- but the meaning that erupts as a result of this interaction: an added value (Chion, 1993) or an extra meaning (Fowler, 1986:69) that goes beyond the mere sum of both narrations.

\section{NOTES}

1. For an outline of the representation of paralinguistic signs in dialogue writing, see Chaume, 1997.

2. In dubbing, the translator who also adapts dialogues (dialogue writing), has to break his/her translation into blocks of several lines. These units are known as takes, a breaking down of the translation into meaningful segments which vary according to the number of lines or to the time of each take.

\section{REFERENCES}

Agost, R. (1997): “Diversitat tipològica i traducció audiovisual,” in Burdeus, M.D., M. Garcia Grau and J. Peraire (eds.): La diversitat discursiva, Castelló, Universitat Jaume I. Col. Summa / Filologia (7), pp. 289-305.

Agost, R. (1999a): Traducción y doblaje: palabras, voces e imágenes, Barcelona, Ariel.

Agost, R. (1999b): "Serialitat i traducció," in Benet, V. and E. Nos (eds.): Cuerpos en serie, Castelló, Universitat Jaume I. Col. Estudis sobre la Traducció, 6, pp. 91-106.

Agost, R. and F. Chaume (eds.) (2001): La traducción en los medios audiovisuales, Castelló, Universitat Jaume I. Col. Estudis sobre la Traducció, 7.

Ballester Casado, A.R. (2000): Traducción y nacionalismo. La recepción del cine americano en España a través del doblaje (1928-1948), Granada, Comares.

Ballester Casado, A.R. (2001): "Doblaje y nacionalismo: El caso de Sangre y Arena," in Agost, R. and F. Chaume (eds.): La traducción en los medios audiovisuales, Castelló, Universitat Jaume I. Col. Estudis sobre la Traducció, 7, pp. 165-175.

Bartrina, F., and E. Espasa (2001): "Doblar y subtitular en el aula: el reto hacia la profesionalización mediante la didáctica," in Pajares, E., R. Merino and J.M. Santamaría (eds.), pp. 429436.

Chaume, F. (1997): “Translating non-verbal communication in dubbing," in Poyatos, F. (ed.): Nonverbal Communication and Translation, Amsterdam, John Benjamins, pp. 315-326.

Chaume, F. (2001): "La pretendida oralidad de los textos audiovisuales y sus implicaciones en traducción," in Agost, R. and F. Chaume (eds.), pp. 77-88.

Chion, M. (1993): La audiovisión, Barcelona, Paidós, pp. 77-88.

Delabastita, D. (1989): "Translation and Mass-Communication: Film and TV Translation as Evidence of Cultural Dynamics," Babel 35-4, pp. 193-218. 
Díaz Cintas, J. (1998): "Propuesta de un marco de estudio para el análisis de subtítulos cinematográficos," Babel 44-3, pp. 254-267.

Espasa, E. and F. BArtrina (forthcoming): “Teaching Audiovisual Translation," in New Trends in Translator Education, Amsterdam, John Benjamins.

Fowler, R. (1986): Linguistic Criticism, Oxford, Oxford University Press.

Franco, E. (2001): "Inevitable Exoticism: The Translation of Culture-Specific Items in Documentaries," in Agost, R. and F. Chaume (eds.), pp. 177-181.

Gregory, M. y S. Carroll (1978): Language and Situation. Language Varieties and Their Social Contexts, London, Routledge and Kegan Paul.

Gutiérrez Lanza, C. (1999): Traducción y censura de textos cinematográficos en la España de Franco: doblaje y subtitulado inglés-español (1951-1975), Doctoral Thesis, Universidad de León (Spain), Oct. 1999.

Gutiérrez Lanza, C. (2001): “Traducción audiovisual," in Pajares, E., R. Merino and J.M. Santamaría (eds.), pp. 383-388.

Hatim, B. and I. Mason (1990): Discourse and the translator, London, Longman.

Herbst, T. (1987): "A pragmatic translation approach to dubbing," EBU Review. Programmes, Administration, Law, 38-6, pp. 21-23.

IzARD, N. (1999): Traducció audiovisual i creació de models de llengua en el sistema cultural català: Estudi de cas del doblatge d'Helena, Doctoral Thesis, Universitat Pompeu Fabra.

Karamitroglou, F. (2001). towards a Methodology for the investigation of Norms in audiovisual translation. The choice between subtitling and Revoicing in children's programmes in Greece. amsterdam and Atlanta: Rodopi.

Mayoral, R., Kelly, D. and N. Gallardo (1988): "Concept of Constrained Translation. NonLinguistic Perspectives of Translation," Meta 33-3, pp. 356-367.

Mendieta, S. (1993): Manual de estilo de TVE, Barcelona, Labor and RTVE.

Pajares, E., R. Merino and J.M. Santamaría (eds) (2001): Transvases culturales: Literatura, Cine, Traduccíon 3, vitoria-Gasteiz, universidad del País Vasco.

Televisió de Catalunya (1997): Criteris Lingüístics sobre Traducció i Doblatge, Barcelona, Edicions 62.

Titford, G. (1982): “Subtitling. Constrainted translation,” Lebende Sprachen 27 (3), pp. 113-116. Whitman, C. (1992): Through the Dubbing Glass, Frankfurt am Main, Peter Lang.

Zabalbeascoa, P. (1993): Developing Translation Studies to Better Account for Audiovisual Texts and Other New Forms of Text Production, Doctoral Thesis, Universitat de Lleida.

\section{AUDIOVISUAL MATERIAL CITED}

Sarafina (Darrell James Roodt, 1992)

The Wizard of $\mathrm{Oz}$ (Victor Fleming, 1939) 